\title{
A MULTI-MILLIAMPERE POLARIZED AND UNPOLARIZED NEGATIVE ION SOURCE FOR IUCF*
}

\author{
V. P. Derenchuk ${ }^{\dagger}$, IUCF, Bloomington, IN 47408, USA \\ A.S. Belov, INR, Troitsk, Moscow Region 117312, Russia
}

\begin{abstract}
The pulsed polarized negative ion source (CIPIOS) for the Indiana University Cooler synchrotron produces multi-milliampere beams for injection into the Cooler Injector Synchrotron (CIS). In normal operation, the unpolarized beam intensity at the source has exceeded $30 \mathrm{~mA}$ peak and for polarized $\mathrm{H}^{-}$and $\mathrm{D}^{-}$beams over $1.5 \mathrm{~mA}$ peak. The FWHM of the beam pulse is $150 \mu \mathrm{s}$, the emittance for $90 \%$ of the beam is less than $1.5 \mathrm{~B}$ $\mathrm{mm}-\mathrm{mr}$ normalized and the nominal polarization is $80 \%$ or greater for both beams. At these peak intensities, the source operates between $0.8 \mathrm{~Hz}$ and $2 \mathrm{~Hz}$. At greater repetition rates, the peak polarized beam intensity decreases slowly.
\end{abstract}

\section{INTRODUCTION}

At Indiana University (IUCF) an atomic beam source (ABS) with a resonant charge-exchange ionizer produces polarized and unpolarized $\mathrm{H}^{-}$and $\mathrm{D}^{-}$ions[1] which are accelerated through an RFQ/DTL to an energy of $7 \mathrm{MeV}\left(4 \mathrm{MeV}\right.$ for $\left.\mathrm{D}^{-}\right)$. This beam fills the Cooler Injector Synchrotron (CIS)[2] using the strip injection technique and after acceleration to $202.8 \mathrm{MeV}$ is extracted and used to fill the Cooler synchrotron[6]. The ABS of this Cooler Injector Polarized Ion Source (CIPIOS) is equipped with a pulsed source of gas and RF power in order to take advantage of higher flow rates, similar to a source built by Belov at the Institute for Nuclear Research of the Russian Academy of Sciences (INR)[3]. For polarized ion beam production, permanent magnet sextupoles are used to focus the atomic beam into a resonant charge-exchange ionizer. The plasma injector and extraction system for the resonant charge-exchange ionizer was built at INR in Troitsk and is similar to their test bench ionizer[4]. The ionizer uses the large cross-section, $10^{-14} \mathrm{~cm}^{2}$ for resonant charge- exchange between low energy $(10 \mathrm{eV})$ $\mathrm{D}^{-}\left(\mathrm{H}^{-}\right)$ions and polarized $\mathrm{H}^{\circ}\left(\mathrm{D}^{\circ}\right)$ atoms [5]. The ionizer consists of a plasma source with a Cs coated converter to produce the negative ions. This plasma is confined along the axis of the ionizer solenoid field. The large flux of negative ions from the plasma source is extracted and is used as an intense source of unpolarized beam for the accelerators with up to $25 \mathrm{~mA}$ of unpolarized $\mathrm{H}^{-}$and $30 \mathrm{~mA}$ of $\mathrm{D}^{-}$ion. Several weeks of maintenance free unpolarized and polarized

\footnotetext{
*Work supported by grants from Indiana University and National Science Foundation PHY-9724216 and PHY-9314783.

†laddie@iucf.Indiana.edu
}

operation has been demonstrated. Polarized $\mathrm{H}^{-}$and $\mathrm{D}^{-}$ beam intensity is $1.5 \mathrm{~mA}$ peak and with nominal polarizations of $80 \%$ and $85 \%$ respectively. The pulse FWHM is about $150 \mu \mathrm{s}$ ( $>200 \mu$ s for unpolarized beam) and can operate at a repetition rate up to $4 \mathrm{~Hz}$ with the existing pumping scheme. Failures during operation are rare and mean time between maintenance for unpolarized operation is in excess of 1000 hours or 41 days. Polarized operation requires maintenance every 12 days on the average to regenerate the cold nozzle and cryopumps.

Further development work by Belov on the test bench at INR has resulted in unpolarized beam currents that exceed $100 \mathrm{~mA}$ (up to $150 \mathrm{~mA}$ observed for $\mathrm{H}^{-}$)[8] and polarized currents of $2.5 \mathrm{~mA}[9]$ at repetition rates of $10 \mathrm{~Hz}$ and a duty factor of $2 \times 10^{-3}$. The high reliability proven at IUCF in combination with these high brightness unpolarized beams makes this source an ideal choice for a high energy accelerator facility.

\section{OPERATION}

\subsection{ABS Operation}

Hydrogen gas is dissociated in a Pyrex tube using an RF pulse coupled to the gas through a coil. An $80 \mathrm{~K} \mathrm{He}$ refrigerator cools the aluminum nozzle.

The dissociator in the ABS operates in a pulsed mode with the following characteristics:

- Pulsed RF supply: Two tube oscillator with pulsed anode voltage. $5 \mathrm{~kW}$ max output for $1 \mathrm{~ms}$ duration at $4 \mathrm{~Hz} . \quad 2.0 \mathrm{~kW}$ peak at $35 \mathrm{MHz}$ during normal operation.

- Pulsed gas valve: General Valve Corp. Series 9 with a $3.3 \Omega$ coil. Gas flow is $7.4 \times 10^{17}$ molecules/pulse.

- Pulsed valve p.s.: A home built 300V switch, rise time $<5 \mu \mathrm{s}$, width variable to $1 \mathrm{~ms}$ is used.

Atomic hydrogen or deuterium is ejected through the $2.2 \mathrm{~mm}$ nozzle exit and is collimated by a $4 \mathrm{~mm}$ skimmer just upstream of a permanent magnet sextupole triplet. A fourth sextupole is an electromagnet with a $31 \mathrm{~mm}$ and permanent magnet loaded pole tips to achieve a pole tip field in excess of 1.1 Tesla. It focuses the atomic beam into the ionizer.

Atoms obtain nuclear polarization only after passing through transition units after electron spin is selected by the sextupoles. Two transition units for polarized $\mathrm{H}$ beam and three transition units for the production of polarized D can be rapidly switched on and off. The 
nuclear polarized atoms reach a $1 \mathrm{~cm}$ diameter focus inside the ionizer solenoid, about $5 \mathrm{~cm}$ beyond the single grid extraction system.

Table 1: Sextupole Specifications. Position is measured from the beam exit at end of cold nozzle to the entrance of the magnet.

\begin{tabular}{|l|llll|}
\hline & PM Mag1 & PM Mag2 & PM Mag3 & PM Mag4 \\
\hline Position & $6.0 \mathrm{~cm}$ & $9.5 \mathrm{~cm}$ & $15.5 \mathrm{~cm}$ & $100 \mathrm{~cm}$ \\
$\mathbf{R}_{\text {entrance }}$ & $4.78 \mathrm{~mm}$ & $7.10 \mathrm{~mm}$ & $9.30 \mathrm{~mm}$ & $15.5 \mathrm{~mm}$ \\
$\mathbf{R}_{\text {exit }}$ & $6.42 \mathrm{~mm}$ & $9.01 \mathrm{~mm}$ & $9.72 \mathrm{~mm}$ & $15.5 \mathrm{~mm}$ \\
Length & $2.5 \mathrm{~cm}$ & $5.0 \mathrm{~cm}$ & $6.0 \mathrm{~cm}$ & $22.7 \mathrm{~cm}$ \\
B $_{\text {pole tip }}$ & $1.66 \mathrm{~T}$ & $1.62 \mathrm{~T}$ & $1.15 \mathrm{~T}$ & $1.10 \mathrm{~T}$ \\
\hline
\end{tabular}

Two $1500 \mathrm{l} / \mathrm{s}$ turbo pumps backed by a roots blower and mechanical pump on the dissociator section and two $1500 \mathrm{l} / \mathrm{s}$ cryopumps on the sextupole section differentially pump the ABS. Only the $4 \mathrm{~mm}$ skimmer connects the two chambers.

\subsection{Ionizer Operation}

The charge exchange ionizer is comprised of a pulsed plasma source with a cesiated converter assembly that produces low energy plasma rich in $\mathrm{D}^{-}$ ions. The plasma source ejects $\mathrm{H}$ or $\mathrm{D}$ plasma through the converter into a 0.1 Tesla solenoid where ionization takes place. Charge exchange takes place in the solenoid between the negative plasma ions and neutral polarized atoms. A polarized beam of negative $\mathrm{H}^{-}$ions and a high intensity beam of unpolarized $\mathrm{D}^{-}$ions are formed when the extraction potential is pulsed to $25 \mathrm{kV}$. To produce polarized $\mathrm{D}^{-}$and unpolarized $\mathrm{H}^{-}$, the feed gas for the ABS and ionizer is switched.

Further improvements of the CIPIOS ionizer and extraction system should result in a doubling of the unpolarized beam currents. $\mathrm{Up}$ to $60 \mathrm{~mA}$ of unpolarized $\mathrm{D}^{-}$beam, $45 \mathrm{~mA}$ of $\mathrm{H}^{-}$and $2.5 \mathrm{~mA}$ of polarized beam is expected within the same emittance.

The ionizer is pumped by one $2200 \mathrm{l} / \mathrm{s}$ turbo pump backed by a $500 \mathrm{l} / \mathrm{s}$ turbo-pump and mechanical pump in series and one $1500 \mathrm{l} / \mathrm{s}$ cryopumps.

The pulsed ionizer timing is adjusted to allow for the approximately $600 \mu \mathrm{s}$ drift time of the atoms from the ABS. Some characteristics of the ionizer are:

- Pulsed arc supply: IUCF built $300 \mathrm{~A}_{\text {peak }}$, regulated to $\pm 5 \mathrm{~A}$ during the pulse. Max pulse length $=1 \mathrm{~ms}$.

- Pulsed gas valve: Built at Institute for Nuclear Research, Troitsk, Russia. Inlet pressure is $40 \mathrm{psia}$ hydrogen or deuterium. Gas flow is $8.3 \times 10^{17}$ molecules/pulse.

- Pulsed valve supply: IUCF built, $300 \quad \mathrm{~V}_{\text {peak }}$ semiconductor switch.

\section{CIPIOS - CIS Injection Layout}

Beam Properties

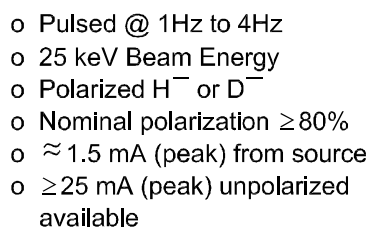

Figure 1 Schematic of ion source and LEBT showing the entrance to the RFQ. The beam is extracted from the ionizer toward the ABS and is then deflected downward with a magnetic bend and towards the RFQ with an electrostatic bend. This results in a nearly vertical polarization at the RFQ entrance. 
- Converter: Molybdenum converter operates at

- 400C with a thin Cesium coating generated by Cesium Chromate in a matrix of Titanium powder.

- Ionizer Solenoid: Typical operation in ionization region is with a 0.1 Tesla field strength.

\section{BEAM PROPERTIES}

Properties of the polarized and un-polarized beams from CIPIOS are listed below.

\subsection{Polarized Beam Properties}

For $\mathrm{H}^{-}$beam:

- Beam Intensity: $\geq \mathbf{1 . 5 m A}$ peak after mass analysis sustainable for several days, $1.2 \mathrm{~mA}$ average for long-term operation.

- Pulse shape: FWHM $150 \mu \mathrm{s}$.

- Emittance: 1.2 $\pi-\mathrm{mm}-\mathrm{mrad}$ normalized for $90 \%$ of the $25 \mathrm{keV}$ beam.

- Polarization: $p_{z}=0.80 \pm 0.01$ for two states.

For $\mathrm{D}^{-}$beam:

- Beam Intensity: $\geq \mathbf{1 . 5 m A}$ peak after mass analysis sustainable for several days, $1.2 \mathrm{~mA}$ average for long-term operation.

- Pulse shape: FWHM $175 \mu$ s.

- Emittance: $1.25 \pi-\mathrm{mm}-\mathrm{mrad}$ (estimated) normalized for $90 \%$ of the $25 \mathrm{keV}$ beam.

- Polarization, vector states:

$\mathrm{p}_{\mathrm{z}}=+0.85 \pm 0.01,-0.70 \pm 0.01, \mathrm{p}_{\mathrm{zz}}=+0.89 \pm 0.01,0.70 \pm 0.01$ for two vector states.

$\mathrm{p}_{\mathrm{zz}}=+0.88 \pm 0.01,-1.59 \pm 0.01, \mathrm{p}_{\mathrm{z}}=0.02 \pm 0.01,0.01 \pm 0.01$ for two pure tensor states.

\subsection{Unpolarized Beam Properties}

For $\mathrm{H}^{-}$beam:

- Beam Intensity: $\geq \mathbf{2 0 m A}$ peak after mass analysis, sustainable for long-term operation.

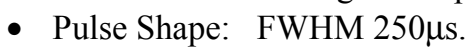

- Emittance: $1.55 \pi \mathrm{mm}$ mrad normalized for $90 \%$ of the $25 \mathrm{keV}$ beam at the RFQ .

For $\mathrm{D}^{-}$beam:

- Beam Intensity: $\geq 25 \mathrm{~mA}$ peak after mass analysis, sustainable for long-term operation.

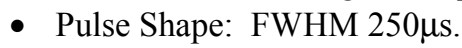

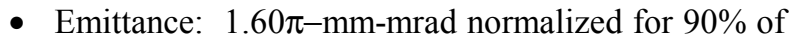
the $25 \mathrm{keV}$ beam at the RFQ

\section{CONCLUSION}

A increase of more than $50 \%$ for polarized and unpolarized beams is expected for CIPIOS by the fall of 2001. The result will be unpolarized beam currents of up to $60 \mathrm{~mA}$ peak in $1.60 \pi-\mathrm{mm}$-mrad and polarized beam intensities of $2.4 \mathrm{~mA}$ with an emittance of $1.2 \pi-\mathrm{mm}-\mathrm{mrad}$ normalized and $80 \%$ polarization. The test bench source at INR has produced unpolarized beam intensities in excess of $100 \mathrm{~mA}$ peak with FWHM of $>200 \mu \mathrm{s}$ at $10 \mathrm{~Hz}$. With this expected increase in beam current and demonstrated 1500 hours of operation between required maintenance and failures, this type of source is a candidate for highenergy accelerators requiring both polarized and unpolarized beams.

\section{REFERENCES}

[1] V.P. Derenchuk, A.S. Belov and W.M. Lozowski, Proc. Conf. of Polarized Sources and Targets, Erlangen, Germany 1999, A.Gute, S.Lorenz, and E.Steffens eds., ISBN 3-00- 005510-X (1999) 64.

[2] D.L. Friesel et al, Proc. 1997 Particle Acc. Conf., IEEE 97CH36167, 2811 (1997).

[3] A.S. Belov et al, Nucl. Instr. Methods A239, 443 (1985).

[4] A.S. Belov et al, Rev. Sci. Instr. 67(3), 1293 (1996).

[5] W. Haeberli, Nucl. Instr. Methods 62, 335 (1968).

[6] D.L.Friesel et al, Proc. 7th European Particle Acc. Conf., Vienna, Austria (2000), Austrian Academy of Sciences Press, J.-.Laclare, W.Mitaroff, Ch.Petit-Jean-Genaz, J.Poole, M.Regler eds.,539.

[7] D.L.Friesel et al, Proc. 7th European Particle Acc. Conf., Vienna, Austria (2000), Austrian Academy of Sciences Press, J.-.Laclare, W.Mitaroff, Ch.Petit-Jean-Genaz, J.Poole, M.Regler eds.,539.

[8] A.S. Belov, private communication.

[9] A.S. Belov et al, SPIN 2000, Osaka, Japan (2000) to be published.

[10]For additional information about CIPIOS browse to http://sauron.iucf.indiana.edu/CIPIOS/cipios main .html. 